\title{
Right ectopic intrathoracic kidney: Unusual clinical presentation in a young patient affected by scrotal varicocele
}

\author{
Lucio Dell'Atti, Andrea Benedetto Galosi \\ Department of Urology, University Hospital "Ospedali Riuniti”, Ancona, Italy.
}

\begin{abstract}
Summary Intrathoracic kidney is a partial or complete displacement of the kidney above the hemidiaphragm into the mediastinal compartment of the thorax. It is usually seen as an incidental finding discovered on chest radiograph or abdominal ultrasound. However computed tomography consents the correct detection of intrathoracic masses and defines their shape, size, and extent. We here report a case of ectopic thoracic kidney in a 22-year-old man who had a long history of scrotal discomfort associated with right varicocele. Frequently, this ectopia does not affect renal function and the stretched ureter provides good drainage. In literature, a small number of cases shows that varicocele is a possible mode of presentation of kidney tumors, but this is the first case of varicocele secondary to intrathoracic kidney ectopia.
\end{abstract}

KEY WORDS: Renal ectopia; Intrathoracic kidney; Varicocele. Submitted 16 August 2017; Accepted 21 September 2017

\section{INTRODUCTION}

Intrathoracic kidney is a partial or complete displacement of the kidney above the hemidiaphragm into the mediastinal compartment of the thorax (1). This kidney ectopia is a rare clinical condition, and represents less than $5 \%$ of all renal ectopias (2). It is usually seen as an incidental finding discovered on chest radiograph or abdominal ultrasound (3). We here report an unusual case of ectopic thoracic kidney in a young man who had a long history of scrotal discomfort associated with right varicocele.

\section{Case report}

A 22-years-old male patient presented to our Department of Urology for chronic scrotal pain and discomfort. On the physical examination, we found no signs of lymphadenopathy in the groin region and a grade 3 isolated right-sided varicocele, while abdominal examination revealed no palpable masses. A scrotal ultrasonography study, using a $10 \mathrm{MHz}$ linear probe, revealed a right-sided varicocele showing reflux flow confirmed by scrotal Doppler ultrasonography. The patient underwent also renal and bladder ultrasonographic study; the right kidney was infeasible to study because of the impossibility to find it. However, the abdominal ultrasound study showed a normal left kidney and an empty bladder.
Urologist decided to perform a Computed Tomography (CT) study in order to evaluate the right kidney. CT scan showed the presence of ectopic kidney in the intrathoracic location on the right side with normal contrast excretion and nondilated pelvicalyceal system (Figure 1). A Magnetic Resonance Imaging (MRI) study was also performed to assess normal functioning of the intrathoracic kidney (Figure 2). The patient underwent right varicocelectomy with microsurgical subinguinal approach. After the procedure the patient was discharged without any surgical treatment after one day of safe observation period and followed-up on outpatient basis.

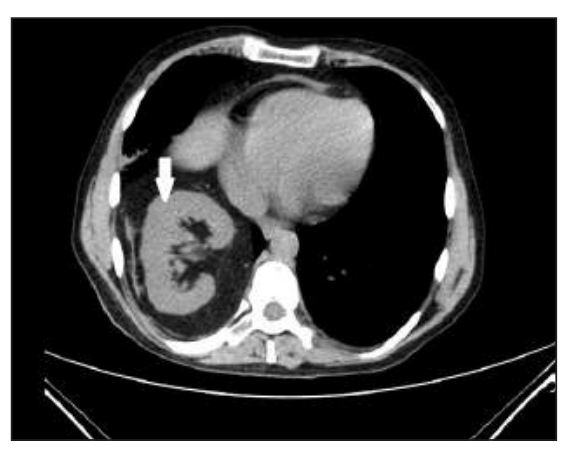

Figure 1.

Axial CT scan at Th 8 level shows the right kidney situated in the right posterior inferior thorax (white arrow).

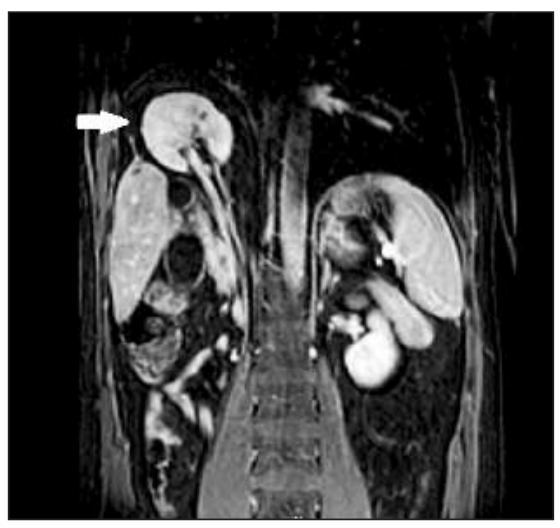

Figure 2.

MRI T2

sequence on sagittal plane confirms the presence of ectopic kidney in the intrathoracic location on the right side with nondilated pelvicalyceal system (white arrow).

\section{Discussion}

The first case of intrathoracic kidney was observed by Wolfromm in 1940 using retrograde pyelography (4). Since then, very few such cases ( 200$)$ have been reported. 
This ectopia shows male predominance and occurs more commonly on the left than on the right side (5). Thoracic kidney has been described in four types: true ectopia, diaphragm eventration, diaphragmatic hernia, and traumatic diaphragm injuries (6). Thoracic kidneys are usually asymptomatic and function normally $(2,3)$. The diagnosis is mostly incidental, which was also seen in our patient (5). The diagnosis is most usually made following a routine chest radiograph in which the affected hemidiaphragm is elevated slightly. Historically, the role of excretory urography has been reported for the diagnosis of a thoracic mass, and its use eliminated the need for further investigation and intervention (6). However, this is now largely replaced by the $\mathrm{CT}$, which consents the detection of intrathoracic masses, defines their shape, size, and extent.

It can diagnose function, stones and visualize vascular and ureteral anatomy (7). MRI has also been used to diagnose it (1). The etiology of a varicocele is undoubtedly multi-factorial and encloses two pathophysiological causes such as absent or incompetent venous valves, and the angle insertion of the left internal spermatic vein into the left renal vein. However, the etiology of a right-sided varicocele may be different. The pathological causes are: a tumor invasion, an extrinsic compression by an intraabdominal tumour, a damage of the venous drainage of the pampiniform plexus by venous thrombosis (8).

In clinical practice an extended ultrasound examination is usually made for the reported association between a renal tumour presenting as an acute varicocele $(8,9)$.

In literature, a small number of cases shows that varicocele is a possible mode of presentation of kidney tumors, but this is the first case of varicocele secondary to intrathoracic kidney ectopia (9). Frequently, this ectopia does not affect renal function and the stretched ureter provides good drainage; therefore it does not need any further intervention (10).

\section{REFERENCES}

1. Al-Saqladi AW, Akares SA. Intrathoracic kidney in a child with literature review. Saudi J Kidney Dis Transpl. 2015; 26:349-54.

2. Donat SM, Donat PE. Intrathoracic kidney: a case report with a review of the world literature. J Urol. 1988; 140:131-33.

3. Sözübir S, Demir H, Ekingen G, Güvenç BH. Ectopic thoracic kidney in a child with congenital diaphragmatic hernia. Eur J Pediatr Surg. 2005; 15:206-9.

4. Wolfromm MG. Situation du rein dans l'eventration diaphragmatique droite. Mem Acad Chirur. 1940; 60:41-47.

5. Drop A, Czekajska-Chehab E, Maciejewski R, et al. Thoracic ectopic kidney in adults. A report of 2 cases. Folia Morphol. 2003; 62:313-16.

6. Sidhu R, Gupta R, Dabra A, et al. Intrathoracic kidney in an adult. Urol Int. 2001;66:174-5.

7. Clarkson LM, Potter S. Case report. An unusual thoracic mass. Br J Radiol. 2009; 82:27-8.

8. Lorenc T, Krupniewski L, Palczewski P, et al. The value of ultrasonography in the diagnosis of varicocele. J Ultrason. 2016; 16:359-70

9. El-Saeity NS, Sidhu PS. "Scrotal varicocele, exclude a renal tumour". Is this evidence based? Clin Radiol. 2006; 61:593-99.

10. Jefferson KP, Persad RA. Thoracic kidney: a rare form of renal ectopia. J Urol. 2001; 165:504.

\section{Correspondence}

Lucio Dell'Atti, MD, PhD

dellatti@hotmail.com

Department of Urology - Marche Polytechnic University

University Hospital "Ospedali Riuniti".

via Conca 71, 60126 Torrette, Ancona, Italy

Andrea Benedetto Galosi, MD

Department of Urology, University Hospital "Ospedali Riuniti",

Ancona, Italy 